\title{
Bolsas de produtividade em pesquisa: educaçáo física, fisioterapia, fonoaudiologia e terapia ocupacional
}

\author{
Brasília Maria Chiari ${ }^{\mathrm{a}}$, Débora B Grossi ${ }^{\mathrm{b}}$, Fernanda D Fernandes ${ }^{\mathrm{b}}$, Leslie P Ferreira ${ }^{\mathrm{c}}$, \\ Marco Túlio de Mello ${ }^{d}$, Pedro C Hallale, Sérgio T Fonseca ${ }^{\mathrm{d}}$ \\ ${ }^{a}$ Universidade Federal de São Paulo - UNIFESP, São Paulo, SP, Brasil. \\ bUniversidade de São Paulo - USP, Ribeirão Preto, SP, Brasil. \\ 'Pontifícia Universidade Católica de São Paulo - PUC-SP, São Paulo, SP, Brasil. \\ ${ }^{d}$ Universidade Federal de Minas Gerais - UFMG, Belo Horizonte, MG, Brasil \\ eUniversidade Federal de Pelotas - UFPel, Pelotas, RS, Brasil.
}

As bolsas de produtividade em pesquisa (PQ) distribuídas anualmente pelo Conselho Nacional de Desenvolvimento Científico e Tecnológico (CNPq) historicamente geram uma série de inquietaçôes na comunidade científica. Com o objetivo de esclarecer esta comunidade em relação aos critérios adotados pelo Comitê de Assessoramento (CA) Multidisciplinar em Saúde para concessão de bolsas PQ, resolvemos produzir este texto.

Um ponto fundamental é ressaltar que as bolsas PQ deste CA são distribuídas prioritariamente para pesquisadores com formação inicial nas áreas do comitê e vínculo institucional com unidades, departamentos ou programas de pós-graduação das áreas. Atividades de orientação em programas não credenciados pela Coordenação de Aperfeiçoamento de Pessoal de Ensino Superior (CAPES) são desconsideradas, assim como produçóes científicas não relacionadas com as áreas do comitê.

Deve-se destacar que existem critérios mínimos para ingresso em cada nível, publicamente divulgados no sítio do $\mathrm{CNPq}$ na internet. Chama atenção que continuamos a receber inúmeros pedidos que não se enquadram nesses critérios mínimos, inclusive de alunos de graduação ou pós-graduação.

Um diagnóstico da situação do CA é necessário. A Educação Física possui atualmente 85 bolsas vigentes, a Fisioterapia e a Terapia Ocupacional possuem 65 cotas e a Fonoaudiologia tem 51 bolsas PQ. As bolsas da Educação Física estão distribuídas entre oito estados da Federação, sendo que 40\% estáo alocadas a docentes do Estado de São Paulo. As bolsas da Fisioterapia e Terapia Ocupacional estáo alocadas a pesquisadores de sete estados, sendo que 63\% dos bolsistas trabalham no Estado de São Paulo. $\mathrm{Na}$ Fonoaudiologia, as bolsas estão concentradas em seis estados, sendo $71 \%$ delas alocadas a pesquisadores vinculados a instituiçôes paulistas.

Do total de bolsas do CA, $62,5 \%$ são de nível $2,18,5 \%$ são $1 \mathrm{D}, 5,5 \%$ são $1 \mathrm{C}, 8,5 \%$ são do nível $1 \mathrm{~B}$ e $5,0 \%$ são do nível 1A. Estes percentuais estão em desacordo com as normas do CNPq, que sugerem $10 \%$ das bolsas nos níveis $1 \mathrm{~A} \mathrm{e} 1 \mathrm{~B}$ e $50 \%$ no nível 2. O CA redigiu documentos à direção do $\mathrm{CNPq}$ solicitando reversão desse cenário, com aumento das cotas 1 , em especial nos níveis $1 \mathrm{~A} \mathrm{e} 1 \mathrm{C}$. Chama atenção também que, nos últimos três julgamentos, não houve qualquer alocação de cotas novas para nosso CA. O assunto também foi abordado em documento recente enviado à direção do CNPq.

A seguir, apresentaremos algumas informações sobre o julgamento das bolsas PQ no ano de 2015. A tarefa mais complexa da avaliação foi definir os indicadores a serem incluídos no algoritmo de cálculo, com respectivos pesos. O CA optou por utilizar cinco indicadores, com os seguintes pesos: produção científica no período avaliado (35\%), orientaçôes (25\%), índice H do Institute for Scientic Information - ISI (20\%), 
média de citaçôes por artigo, calculada a partir da base Scopus (15\%), e projeto de pesquisa submetido (5\%). Deve-se ressaltar que tais critérios somente foram aplicados aos solicitantes que se enquadravam nos critérios mínimos divulgados no sítio do CNPq. Por exemplo, pesquisadores com atuação predominante em outras áreas ou que não atingiam os critérios mínimos de orientação e produção científica foram eliminados nesse primeiro estágio da avaliação.

Cada um desses indicadores possui um algoritmo específico de cálculo padronizado, sendo que o escore final varia de 0 a 100 . No caso dos projetos, são avaliados por dois pareceristas ad-hoc. O conceito "Excelente" equivale à nota 5 , o conceito "Bom" equivale à nota 3 , o conceito "Regular" equivale à nota $2 \mathrm{e}$ o conceito "Fraco" equivale à nota 1. A média das duas avaliaçôes é utilizada no escore final. No julgamento de 2015, apenas 16\% dos projetos foram classificados como "Excelente" pelos dois avaliadores.

No que se refere ao índice $\mathrm{H}$, inicialmente é feito o cálculo do percentil 95 da distribuição, sendo este valor equivalente ao escore máximo (20). O escore de cada pesquisador é calculado por regra de três em comparaçáo ao valor do percentil 95. Em termos brutos, o índice $\mathrm{H}$ médio dos solicitantes no ano de 2015 foi de 5,2, variando de 0 a 19. O percentil 95 correspondeu ao valor 13 . O índice $\mathrm{H}$ médio dos solicitantes da Educação Física foi de 5,4, comparado com 6,0 na Fisioterapia e Terapia Ocupacional e 3,0 na Fonoaudiologia.

Em relação às citaçôes, o cálculo é feito de forma idêntica ao utilizado para o índice $\mathrm{H}$. Em termos brutos, a média de citaçóes por artigo foi de 5,6, sendo o escore médio de 5,2 citaçôes/artigo na Educação Física, 6,6 na Fisioterapia e Terapia Ocupacional e 4,0 na Fonoaudiologia.

$\mathrm{O}$ escore de produção científica é calculado de forma complexa. Cada artigo publicado em revistas com fator de impacto acima de quatro equivale a 100 pontos. O peso das publicaçóes em revistas com menor impacto vai decrescendo, chegando a 50 para publicaçóes em periódicos com fator de impacto entre 0 e 0,5 e 10 para produçóes em revistas sem fator de impacto. Artigos publicados em revistas sem revisão por pares são desconsiderados. Cada livro equivale a 80 pontos e cada capítulo de livro equivale a 40 pontos. Um bônus é dado para artigos publicados como primeiro ou último autor, e depois como segundo ou penúltimo autor. Este algoritmo gera um escore contínuo, o qual é depois processado da mesma forma como foi descrito para o índice H e índice de citaçôes.

Nas orientaçôes, são atribuídos três pontos para orientações de doutorado concluídas, dois pontos para supervisōes de pós-doutorado concluídas e um ponto para orientaçôes de mestrado concluídas. Metade desses valores é atribuído a orientaçóes em andamento. O escore final com peso 25 é calculado de forma similar ao realizado para os outros indicadores. No entanto, esse indicador possui valor teto, equivalente à titulação de 0,5 , para doutores, e 1 , para mestre, por ano. Todos os docentes que atingem esses valores recebem o escore máximo no quesito orientaçóes.

O escore contínuo, com peso 100, correlaciona-se com todos os indicadores. A correlaçáo mais forte foi com o índice $\mathrm{H}(\mathrm{r}=0,83)$, seguido da produção científica $(\mathrm{r}=0,73)$, citaçôes médias $(\mathrm{r}=0,66)$, orientaçôes $(\mathrm{r}=0,58)$ e projeto de pesquisa $(\mathrm{r}=0,42)$. O escore médio final foi de 47 pontos entre os solicitantes da Educação Física, 48 entre os solicitantes da Fisioterapia e Terapia Ocupacional e 36 entre os solicitantes da Fonoaudiologia.

Tendo em vista a disponibilidade de cotas de renovação no ano de 2015 , foi possível atender a $30 \%$ da demanda da Educação Física, 31\% da demanda da Fisioterapia e Terapia Ocupacional e 49\% da demanda da Fonoaudiologia. Tais números comprovam a competividade do sistema e estimulam esse CA a buscar o aprimoramento dos critérios de avaliação continuamente.

O CA procedeu entâo a uma série de análises comparando os pesquisadores contemplados e não contemplados com cotas no ano de 2015. Na Educação Física, o índice H médio dos contemplados foi 8,3, contra 2,0 entre os não contemplados. A média de citaçôes foi de 8,2 entre os contemplados e 2,7 entre os não contemplados. Na Fisioterapia e Terapia Ocupacional, as diferenças foram menores. O índice H médio dos contemplados foi de 7,6, comparado com 4,8 entre os não contemplados. As médias de citaçóes foram de 11,1 e 4,1, respectivamente. Na Fonoaudiologia, o índice $\mathrm{H}$ médio dos contemplados foi de 3,6 , contra 1,8 entre os não contemplados. As citaçôes médias foram de 4,6 entre os contemplados e 2,0 entre os náo contemplados.

O CA gostaria de utilizar este espaço para fornecer algumas sinalizaçóes para a área. O preenchimento dos currículos Lattes deve ser aprimorado; detectamos muitos casos de resumos de eventos inseridos como "Artigos Completos Publicados em Periódicos" nos currículos dos solicitantes. Da mesma forma, editoriais 
e cartas ao editor nem sempre foram claramente identificados dessa forma pelos solicitantes. Existe uma tendência no comitê a valorizar cada vez mais a qualidade da produçáo científica, em detrimento de uma avaliação baseada apenas em quantidade. No julgamento de 2014, o escore de produção possuía peso de 50 pontos, tendo sido reduzido para 35 pontos em 2015. O índice $\mathrm{H}$ duplicou de valor, assim como aumentaram os pesos do índice de citaçōes e histórico de orientaçôes.

Não poderíamos deixar de utilizar este espaço para agradecer aos pareceristas ad-hoc do CA. No entanto, algumas reflexões devem ser feitas. Em muitos casos, os pareceres são excessivamente sucintos, impedindo uma compreensão mais adequada dos projetos submetidos. Além disso, deve-se destacar que a avaliação global do parecer ad-hoc para as bolsas PQ deve focar o projeto submetido, e náo o currículo do proponente, o qual é avaliado pelos demais indicadores aqui descritos. Por fim, é fundamental que os pareceristas julguem as propostas com base nos critérios estabelecidos pelo CA.

Por fim, o CA compromete-se a divulgar publicamente os resultados detalhados de todos os julgamentos realizados, tendo como único limite as restriçôes legais impostas pelo CNPq e pela Constituição Federal. Solicitantes devem se sentir à vontade para enviar mensagem eletrônica para os membros do CA caso possuam qualquer dúvida sobre o julgamento ou suas pontuaçóes gerais e específicas para cada indicador.

Este editorial está sendo publicado simultaneamente nas revistas Brazilian Journal of Physical Therapy, Cadernos de Terapia Ocupacional da UFSCar, CoDAS e Movimento, sendo também divulgado no sítio do $\mathrm{CNPq}$. O objetivo desta publicação conjunta é atingir os pesquisadores das diferentes áreas que compóem o CA. Espera-se que esta publicação estimule um amplo debate científico de constante aperfeiçoamento dos critérios de avaliação do CA. 